\title{
O lugar da leitura literária no século XXI
}

\section{The literary reading in the 21st century}

\section{Cleideni Alves do Nascimento* \\ UNEB}

Resumo: O objetivo deste trabalho é analisar e discutir o atual contexto de ensino de literatura no ensino básico brasileiro, e também avaliar o modelo de formação docente nos cursos de Letras. Diferentemente, de outras formas de narrativas, o texto literário tem o potencial de despertar o senso crítico, nos tornando mais atentos às armadilhas da linguagem presentes nos diversos discursos sociais. Partindo de uma concepção que compreende o papel humanizador da literatura, este trabalho se baseia nas concepções de autores como: Calvino, Candido, Compagnon, Petit e Todorov. Observa-se que o ensino de literatura na educação básica, assim como, a formação dos professores não contempla uma abordagem humanista através da leitura literária. Ao contrário, o trabalho realizado é predominantemente de cunho técnico, o que torna o texto literário pouco significativo para o aluno. Faz-se necessário oferecer mais tempo, espaço e uma formação docente que prepare o futuro professor para realizar um trabalho que realmente consiga explorar ao máximo o potencial dos textos literários, e assim formar novos leitores. Mesmo com todas as mudanças que aconteceram nos últimos tempos, a leitura literária ainda é o meio mais eficaz para nos fazer enxergar o mundo sob novas perspectivas.

Palavras-chave: Leitura literária. Ensino. Formação de professores.

\begin{abstract}
The objective of this study is to analyze and discuss the current context of literature teaching in Brazilian basic education and also evaluate the model of teacher education in Literature graduations. Differently from other forms of narratives, the literary text has the potential to develop critical thinking, making us more aware of the language traps present in various social discourses. From a conception which view the humanizing role of literature, this paper is based on ideas of authors such as: Calvino, Candido, Compagnon, Petit and Todorov. It is observed that the literature teaching in basic education, as well as, teachers education does not include a humanistic approach through literary reading. On the opposite, the work is predominantly technical, what makes the literary text negligible for the student. It is necessary to provide more space, time and an education which could prepare future teachers to do a job that can really exploit the potential of literary texts, and thus form new readers. Even with all the changes that have happened in recent times, literary reading is still the most effective way to make us see the world from new perspectives.
\end{abstract}

Keywords: Literary reading. Teaching. Teachers education.

\author{
* Prof ${ }^{a}$ Auxiliar da \\ Universidade do \\ Estado da Bahia \\ Campus X Mestre em \\ Estudos da Linguagem \\ (UEPG); cleideni_ \\ nascimento@yahoo. \\ com.br
}




\section{Introdução}

Em 1984, o escritor italiano Ítalo Calvino foi convidado para ministrar um ciclo de seis conferências na Universidade de Harvard no ano letivo de 1985-86. Ao escolher a temática de suas conferências, Calvino optou por tratar de alguns valores literários que mereciam ser preservados no curso deste milênio. Essas conferências receberiam em italiano o título Lezioni americane - Sei proposte per il prossimo millennio. Às portas do século XXI, o escritor destaca a frequência com que se interrogavam sobre o destino da literatura e do livro na era tecnológica dita pós-industrial. Há quase trinta anos, mesmo com a perspectiva de muitas mudanças para o então novo milênio, Calvino apostou com segurança no futuro da literatura. "Minha confiança no futuro da literatura consiste em saber que há coisas que só a literatura com seus meios específicos nos pode dar.” (CALVINO, 1990, p.11).

Hoje, em pleno século XXI, a reflexão sobre o espaço reservado à leitura literária ainda é uma preocupação entre estudiosos e amantes da literatura. Mas o que mudou durante esse tempo? Poderíamos ainda nos apoiar na afirmação confiante de Calvino sobre o futuro da literatura? Ela ainda resiste às mudanças pelas quais a sociedade contemporânea tem passado?

Talvez o termo que melhor caracterize o mundo atual seria velocidade. A revolução tecnológica não apenas estreitou as distâncias, como também acelerou o ritmo de vida das pessoas. Acontecimentos marcantes ou meras tolices são transmitidos em tempo real para diversos lugares do planeta. E para muitos, estar conectado à "grande rede” se tornou sinônimo de atualização. É inegável a quantidade e diversidade de informações que circulam nos meios digitais. No entanto, boa parte desses dados recai no senso comum, na banalidade e na superficialidade. Nas redes sociais, as novidades nem sempre são novas. E mesmo quando o são, elas envelhecem rapidamente.

A era da rapidez e do imediato tem influenciado, profundamente, o modo de vida moderno. As pessoas querem, neuroticamente, ganhar tempo. Há uma falsa sensação de que precisam de mais tempo para realizar todas as tarefas que gostariam. Esse contexto que dita o ritmo de vida atual parece se estender a todos os âmbitos sociais. Seu alcance atinge as relações pessoais, a produção de conhecimento, relações de trabalho, entre outros. Considerando as diversas mudanças pelas quais o mundo vem passando e que elas têm, gradativamente, impulsionado a aceleração do estilo de vida moderno, a questão a ser colocada é: qual é o lugar da leitura, em especial da leitura literária, no século XXI?

Formas de expressão áudio visual como um filme, um programa de televisão ou um vídeo tem seu tempo de duração já estabelecido. Mas um 
livro não traz a inscrição de quanto tempo levaremos para lê-lo. Não é possível dizer de forma precisa qual será o tempo real de uma leitura. Ao abrir um livro, o leitor não irá simplesmente acompanhar a materialidade linguística de um texto. Ele, provavelmente, fará digressões, reflexões, suposições, comparações e relações. Seu ritmo de leitura será baseado no seu conhecimento prévio e na sua subjetividade. O tempo de cada leitor será único. O certo é que não se trata de uma atividade imediata. Levando em consideração as caraterísticas peculiares à leitura e as exigências dos tempos modernos, haveria ainda tempo para o deleite vagaroso de uma leitura? Teria o livro se tornado um objeto obsoleto na era digital?

Ao longo deste trabalho, discorremos sobre a narrativa como uma necessidade da natureza humana, desempenhando um papel importantíssimo na visão que o indivíduo constrói de si mesmo e do mundo a sua volta. Na sequência, falamos sobre contexto escolar brasileiro de ensino de literatura e a formação de leitores, apontando suas principais deficiências e possíveis alternativas para reverter esse quadro. No entanto, falar sobre formação de leitores pressupõe também a discussão da formação dos formadores de leitores. De que forma a literatura tem sido apresentada aos discentes dos cursos de Letras que futuramente atuarão no ensino básico? Por fim, defendemos o papel da leitura literária no contexto atual, compreendendo que ela age diferentemente de todas as outras formas de expressão humana, influenciando positivamente a construção da identidade do indivíduo que lê.

\section{A narrativa: uma necessidade humana}

Não há e não houve nenhum povo, ao longo da história humana, que não tenha feito uso da atividade narrativa. As próprias histórias que buscam explicar o surgimento da humanidade, nada mais são do que narrativas de cunho religioso ou científico. A vida sempre precisou ser contada, até mesmo como uma tentativa de compreendê-la. Como explicar quem somos, senão através da nossa história? Uma pessoa sem história é alguém sem identidade. "[...] Todos os homens que andam na rua são homens-narrativas, é por isso que conseguem parar em pé.” (LEJEUNE, 2008, p.104). A citação do pesquisador francês, especialista em autobiografia, pode parecer estranha, mas o que ele busca expressar é que cada ser humano se sustenta sobre a sua própria história de vida.

Por muitos e muitos séculos as narrativas se restringiram à oralidade, mesmo porque milhares de povos ao redor do mundo não tinham ou têm um código escrito de suas línguas. O objeto livro, tal qual o conhecemos hoje, é produto do século XIX, quando a impressão em série possibilitou um maior número de obras em circulação. Tradições, conhecimento e experiências têm sido transmitidos de geração a geração através de narrativas 
orais. No entanto, já na primeira metade do século XX, o filósofo e crítico literário alemão Walter Benjamin escreveu sobre a ameaça do fim dessa modalidade de narrativa. "Contar histórias sempre foi a arte de contá-las de novo, e ela se perde quando as histórias não são mais conservadas.” (BENJAMIN, 1994, p. 205). Para o autor, a narrativa como uma forma artesanal de comunicação, que remete a um estilo de produção no qual as mãos ditavam o ritmo de trabalho a ser seguido, perde espaço para um novo estilo - aquele no qual as mãos dão lugar às máquinas.

Já no início da era industrial, exige-se um ritmo de vida mais acelerado. As pessoas não tinham mais tempo para se reunir, contar e ouvir histórias. O romance viria substituir as histórias da oralidade. Mas a sua leitura seria uma experiência solitária, como coloca Benjamin,

Mas o leitor de um romance é um solitário. Mais solitário que qualquer outro leitor (pois mesmo quem lê um poema está disposto a declamá-lo em voz alta para um ouvinte ocasional). Nessa solidão, o leitor do romance se apodera ciosamente da matéria de sua leitura. (1994, p.213).

Benjamin temia pelo desaparecimento da narrativa oral com o advento do romance. Hoje o que assusta é o poder de diversos outros tipos de narrativas que, na maior parte das vezes, tem o propósito de alienar e submeter as pessoas. Entre essas narrativas estão as midiáticas, políticas, religiosas, econômicas, entre outras. As milhares de histórias contadas através dos meios de comunicação e das instâncias oficiais que governam um estado-nação têm influência direta sobre o imaginário popular. A própria ideia de pertencimento a uma nação está fundamentada em uma narrativa nacional. Segundo Hall (2006), as pessoas não são apenas cidadãos/ãs legais de uma nação; elas participam da ideia da nação tal como representada em sua cultura nacional.

As narrativas, de modo geral, exercem um papel direto na construção de identidades. No entanto, há uma distinção entre a forma de atuação das narrativas literárias e de grande parte das demais narrativas que circulam em nosso meio. Tomemos por exemplo as narrativas das telenovelas e dos filmes que seguem o padrão mercadológico (hollywoodiano) de cinema.

As telenovelas apresentam histórias com enredos pobres que, geralmente, giram em torno de conflitos de relacionamento interpessoal. $\mathrm{O}$ desfecho dessas histórias quase sempre é eufórico. Os diversos modelos de representação trazem personagens bem-sucedidas que estão ligadas às classes sociais mais abastadas e a padrões de beleza estabelecidos pela mídia. O pobre, muitas vezes, é representado de maneira estereotipada, mostrando moradores da periferia como malandros, bandidos, "periguetes barraqueiras”, etc. No que diz respeito à transmissão de conhecimento e cultura, muito pouco é apresentado. A linguagem clichê e as expressões desgastadas também não têm nada a acrescentar. 
As narrativas fílmicas que seguem o padrão hollywoodiano se assemelham às telenovelas em alguns aspectos. A história, quase sempre, apresenta uma narrativa linear com um conflito que se resolverá com um final feliz. O protagonista representa um padrão de beleza de origem eurocêntrica e também as classes sociais mais abastadas. Além disso, há os efeitos especiais e as superproduções cinematográficas que atraem e encantam o público desse modelo de cinema.

Em ambos os exemplos apresentados de narrativas que circulam socialmente, temos histórias lineares que trazem um formato de fácil acompanhamento e compreensão, não oferecendo ao telespectador um grau de dificuldade muito alto. No entanto, por trás dessas formas narrativas atraentes, se escondem perigosos discursos. Enquanto imerso no universo fabulado dessas histórias, inconscientemente, o telespectador assimila discursos que agem diretamente sobre a sua identidade.

Esses discursos, implicitamente, comunicam quem deve estar e continuar no poder; dizem que para ser feliz e ter sucesso, você deve consumir o máximo que puder; apresentam a ordem social econômica como algo natural e que você deve se conformar com sua posição nessa ordem; dizem que para você ser aceito, deve seguir um padrão de beleza e comportamento. Enfim, nenhum desses discursos leva o indivíduo à sua emancipação enquanto sujeito. Ao contrário, eles levam o indivíduo a um estado de entorpecimento mental que o faz agir no automatismo. A socióloga francesa Michèle Petit fala sobre esses modelos narrativos,

Existem também processos narrativos que não têm nenhum poder transformador, relatos de si mesmo estereotipados, repetidos à exaustão, que não permitem nenhum movimento diante da lembrança - da mesma forma como existem jogos aos quais nos entregamos maquinalmente e que nos fornece uma simples descarga motora, sem provocar simbolização. (2009, p.129).

Ao se entregar maquinalmente a esse tipo de narrativas, o indivíduo busca escapar da sua realidade, muitas vezes, dura e sem perspectivas. Porém, nesse estado de total entrega, acreditando estar simplesmente se divertindo, ele irá assimilar inconscientemente os discursos apresentados, sem voltar um olhar crítico para o seu contexto social. Assim, esse indivíduo continuará sem perspectivas de modificar ou melhorar as suas condições de vida. E pior ainda, muitos dos problemas que ele enfrenta podem ter origem na influência que tais discursos exercem sobre sua identidade.

As narrativas atravessam, intensamente, nosso quotidiano e precisamos delas para que o nosso cérebro exercite a capacidade de simbolização. “Assim como todos sonham todas as noites, ninguém é capaz de passar as vinte e quatro horas do dia sem alguns momentos de entrega ao universo fabulado.” (CANDIDO, 2004, p.174). No entanto, como já 
foi dito anteriormente, não são todos os tipos de narrativas que nos levam a libertar nossos pensamentos de clichês, preconceitos e de "verdades" construídas ao longo dos séculos. Por essa razão, é necessário estabelecer uma distinção entre narrativas controladoras e libertadoras.

Passaremos à narrativa literária, buscando compreender como ela age no nosso imaginário. Ao contrário do que muitos possam ingenuamente pensar, a leitura literária não é uma simples forma de distração que nos torna alheios ao mundo real. Seu alcance vai muito além do nível de entretenimento. Diferente das narrativas que têm por trás uma grande corporação ou um conjunto de interesses, a narrativa literária é produzida por um autor solitário. Esse autor pode produzir uma obra com o intuito de transmitir seu modo de pensar ao leitor, ou então, com o intuito de levar o leitor a pensar, a questionar a si mesmo e ao mundo ao seu redor.

Ficamos com o escritor que nos leva a questionar e não com aquele que busca nos convencer. O objetivo do primeiro não é explicar o porquê dos fatos, mas sim se deter ao como eles acontecem. "O escritor é o homem que absorve radicalmente o porquê do mundo num como escrever" (BARTHES, 1970, p.33). No entanto, o seu trabalho jamais alcança a plenitude, pois a literatura que para o escritor é um fim, o mundo a devolve como meio. Dessa forma, a literatura seria sempre uma pergunta a ser respondida, nunca uma resposta definitiva. O escritor, que escreve para libertar, está ciente de que seu papel é revelar e não esconder as mazelas da sociedade. "O escritor engajado sabe que a palavra é ação: sabe que desvendar é mudar, e que não se pode desvendar senão tencionando mudar” (SARTRE, 1989, p.20).

A obra literária, através da organização estética da linguagem e da mensagem que transmite, comunica a humanidade em sentido profundo, oferecendo inúmeros modelos de experiências humanas com as quais o leitor pode se identificar, tornando-o, assim, mais sensível à vivência do outro.

Candido (2004) menciona três aspectos que compõem a função da literatura. A atuação simultânea dos três aspectos seria responsável pelo efeito que as produções literárias têm sobre o leitor. Em primeiro lugar, a literatura age porque ela é uma construção de objeto autônomo como estrutura e significado. Segundo, porque ela é uma forma de expressão, isto é, manifesta emoções e a visão do mundo dos indivíduos e dos grupos. E o terceiro aspecto, porque ela é uma forma de conhecimento, inclusive como incorporação difusa e inconsciente. Dentre os três aspectos, o último seria aquele mais conhecido e valorizado pelo senso comum. Seria a ideia de que a leitura torna as pessoas mais cultas e com mais conhecimento. No entanto, o alcance da literatura vai muito além de fornecer conhecimento.

É importante compreender que o efeito que esses aspectos da função literária exercem sobre o leitor resulta da organização estética que o escritor dá à linguagem. "Em palavras usuais: o conteúdo só atua por causa da 
forma, e a forma traz em si, virtualmente, uma capacidade de humanizar devido à coerência mental que pressupõe e que sugere” (CANDIDO, 2004, p.178). Somente através da literatura, a linguagem pode resistir ao que Calvino (1990) chama de epidemia pestilenta. Fenômeno moderno que reduz a linguagem a um uso genérico, casual, descuidado, fazendo com que a palavra perca sua força significativa.

Embora todas as formas de narrativas tratem da vida humana, a narrativa literária pela sua ordenação coerente e pelo seu trabalho artístico comunica muito mais que qualquer outro texto. "A literatura não é a única, mas é mais atenta que a imagem e mais eficaz que o documento, e isso é suficiente para garantir seu valor perene.” (COMPAGNON, 2012, p. 71). O texto literário, enquanto uma produção discursiva autêntica, não tem o intuito de ludibriar o leitor. Ao contrário, ele procura fazê-lo enxergar realidades sociais que por muito tempo se apresentavam como naturais. Para Compagnon (2012), a literatura nos ensinaria a não nos deixarmos enganar pela língua. "Ensinando-nos a não sermos enganados pela língua, a literatura nos torna mais inteligentes, ou diferentemente inteligentes.” (2012, p.49).

Vimos ao longo dessa seção que estudiosos e pesquisadores em literatura apresentam suas percepções conceituais de como o texto literário pode atuar sobre a identidade do indivíduo que lê. No entanto, apenas conhecer o valor transformador da literatura através de teorias, não nos permitiria experimentar de forma plena o potencial dos textos literários. $\mathrm{O}$ leitor comum, mesmo sem ter o conhecimento teórico da forma de atuação do texto literário, consegue encontrar nas obras que lê algo que possa dar sentido à sua vida.

\section{O contexto escolar brasileiro e a formação de leitores}

Ainda que pesquisadores e estudiosos apontem as diversas qualidades da leitura literária, buscando demonstrar a sua importantíssima função intelectual e social na formação identitária de um indivíduo, veremos a seguir que o atual panorama brasileiro não é muito animador. A formação de leitores pode se dar em diferentes contextos sociais, não sendo a escola o único espaço responsável por tal formação. No entanto, a escola deveria ser, por excelência, o principal contexto social formador de leitores. Não é necessário ouvir a opinião de um especialista para constatar que o Brasil é um país de poucos leitores. As pesquisas e avaliações da educação básica mostram um número crescente de analfabetos funcionais, pessoas incapazes de analisar e interpretar criticamente um texto. A constatação de que o Brasil não é um país de leitores pode ser explicada pelo fato de, historicamente, não haver uma preocupação política em incentivar e promover a leitura no contexto escolar com seriedade e de forma continuada. 
O escritor brasileiro Affonso Romano de Sant'Anna discute, no texto "O leitor, onde está o leitor? Ou a crise da escassez e do excesso", a crise paradoxal pela qual todo o sistema ao redor do livro está enfrentando. Segundo Sant’Anna (2012), embora os editores brasileiros revelem que estão publicando livros “demais”, ele observa a situação de outro ângulo.

O Brasil não produz livros “demais”. O Brasil produz leitores de menos. Há que "produzir” o leitor. E não estou falando de alfabetização. Essa cadeia do livro não existe sem o destinatário: o leitor. Não há excesso de livros, há falta de bibliotecas, de livrarias e de leitores. (2012, p.65).

A questão colocada por Sant’Anna é pertinente e, ao mesmo tempo, preocupante. O Brasil não “produz” leitores. Lamentavelmente, políticas de formação de leitores nunca foram prioridade em nosso país. Não se forma leitores de um dia para outro, trata-se de um processo longo e contínuo. A maneira como a literatura tem sido ensinada, nas escolas brasileiras ao longo do tempo, não tem contribuído significativamente para o aumento do número de leitores. De fato, não se ensina a ler literatura, e sim sobre a história da literatura. O cânone tradicional traz uma lista de obras, que na maior parte são representativas de uma literatura nacional. Não questionamos a importância das obras canônicas no contexto de ensino de literatura. No entanto, é questionável sua hegemonia e a falta de espaço para obras literárias não-canônicas.

O contexto de ensino de literatura no Brasil parece não ter acompanhado as mudanças ocorridas nos diversos âmbitos sociais, assim como, na área de produção de conhecimento. A professora e pesquisadora Neide Luzia de Rezende (2013), aponta que embora as abordagens baseadas nas teorias cognitivistas tenham sido amplamente divulgadas no campo da Educação nas últimas décadas, elas não se mostraram capazes de promover na escola brasileira a mudança de práticas escolares que cada vez mais se afastam da leitura literária efetiva. As propostas de uma abordagem interacional apresentadas pelas orientações pedagógicas oficiais brasileiras não têm sido articuladas com o trabalho didático com a literatura.

Diante desse sério problema apresentado no contexto de ensino de literatura na educação básica no Brasil, destacamos duas deficiências que têm agravado essa situação. A primeira delas está relacionada com a formação docente e a segunda com as condições existentes para cumprir os objetivos de ensino de literatura na escola.

A formação docente é um processo importantíssimo, pois ela define o perfil do futuro profissional. Ao longo do curso de formação superior, sua identidade docente é construída não somente pelos discursos que lhe são apresentados, mas principalmente, pelos modelos de docência que ele recebe através da prática de seus próprios professores. Grande parte dos currículos dos cursos de Licenciatura em Letras apresenta uma concepção 
técnica de ensino de literatura, seguindo o modelo convencional da história da literatura. Dentro dessa concepção, o texto literário é reduzido a um mero objeto de estudo que deve ser analisado tecnicamente, como se não tivesse nenhuma relação significativa com o mundo real.

Os professores formados por esse modelo de ensino de literatura irão, certamente, reproduzi-lo na sua prática cotidiana. Eles, na maioria das vezes, não são leitores e cumprem seu trabalho como uma tarefa meramente burocrática, não encontrando nenhum prazer na sua realização. Por sua vez, eles transmitirão aos alunos o mesmo enfado e frustração que sentem no desenvolvimento do seu trabalho com a literatura, e consequentemente, não conseguirão formar leitores. Esse círculo vicioso de formação tem sido o grande vilão no processo de “produção” de novos leitores.

Além da deficiência na formação docente, outra dificuldade são as condições existentes para a atuação do professor. O trabalho com a literatura demanda uma quantidade e variedade razoável de livros e tempo para desenvolver um trabalho mais consistente. Rezende (2013) defende que para o professor realizar seu trabalho com a leitura de maneira crítica e autônoma, ele precisa ter vivenciado essa experiência na sua formação e também precisa de tempo e espaço para isso.

Construir autonomia e visão crítica, tendo a leitura como a maior aliada, supõe que o professor tenha ele próprio vivenciado esse tipo de formação e que o currículo escolar reserve tempo e espaço para isso, uma vez que reflexão, elaboração, escrita e leitura, em especial literária, demandam tempo, num ritmo que não é aquele dos conteúdos objetivos com respostas exatas ou mecanizadas. Ler, refletir, fruir, entender, elaborar, reelaborar, requer mais do que uma ou duas horas semanais constantes numa grade, como sói acontecer. (2013, p.11).

As condições de trabalho oferecidas ao professor e o espaço reservado à literatura no contexto escolar público demonstram o descaso de nossos governantes com a prática da leitura na sociedade brasileira. Um ensino efetivo de literatura pressupõe a leitura de obras literárias. Estudar somente as características de um texto, com base em seu resumo, jamais suplantará a experiência de uma leitura integral. No contexto escolar brasileiro, infelizmente, a literatura, enquanto experiência de leitura, não tem sido contemplada. Não havendo espaço para a leitura, por sua vez, não há espaço para o leitor. Nesse jogo de faz de conta, o sistema educacional cumpre sua obrigação legal de ofertar a disciplina no currículo básico de ensino, sem, contudo, conseguir resultados no mínimo suficientes dentro dos objetivos esperados.

No ano 2000, um contexto desfavorável ao ensino de literatura, muito parecido ao brasileiro, era o francês. A constatação da falência do texto literário na escola francesa levou a propostas oficiais que buscaram 
se adequar à nova realidade social. A análise de cunho meramente técnico das obras literárias passa a dar lugar à leitura cursiva, ou seja, uma leitura autônoma. A subjetividade do leitor começa a ser levada em consideração na construção do sentido da obra.

Dentro dessa nova proposta, há uma mudança de paradigma no que diz respeito à concepção de leitura literária. A pesquisadora francesa Annie Rouxel (2013) diz que tal mudança marca a passagem de uma concepção da leitura literária fundada sobre uma teoria do texto, que postula o leitor implícito, a uma concepção que se interessa pela reconfiguração do texto pelo leitor real e apresenta modos de realização plurais. Rouxel justifica que não se trata de uma abordagem totalmente solta, cabe ao professor orientar e mediar a construção de sentido.

Não se trata, no entanto, de renunciar ao estudo da obra na sua dimensão formal e objetiva, mas ao acolher as impressões do aluno, favorecer neles a descoberta das implicações pessoais na leitura. Trata-se fazê-los sair de uma postura de exterioridade construída face a um objeto escolar para leválos a compreender que a obra dirige-se a eles. (2013, p.206/207).

A partir do momento em que os alunos percebem que a obra literária tem a capacidade de comunicar a experiência humana em sentido amplo, se identificando com as representações presentes na obra, há o despertar de um desejo. A dimensão do desejo e da afetividade na formação do sujeito leitor é muito importante. Quando ele estabelece uma relação de prazer com a leitura, o desejo de novas descobertas literárias e a vontade de compartilhar essas descobertas será uma constante. Contudo, o professor de literatura prescinde de uma formação que lhe ofereça recursos necessários para se alcançar tal objetivo. Todorov (2010) aponta que deve haver uma distinção entre o conhecimento trabalhado durante a formação docente e durante a atuação desse profissional.

No ensino superior, é legítimo ensinar (também) as abordagens, os conceitos postos em prática e as técnicas. O ensino médio, que não se dirige aos especialistas em literatura, mas a todos, não pode ter o mesmo alvo; o que se destina a todos é a literatura, não os estudos literários; é preciso então ensinar aquela e não estes últimos. O professor do ensino médio fica encarregado de uma das mais árduas tarefas: interiorizar o que aprendeu na universidade, mas, em vez de ensiná-lo, fazer com que esses conceitos e técnicas se transformem numa ferramenta invisível. (2010, p.41).

A formação de leitores na escola não é uma tarefa fácil. Para que tal tarefa seja realizada satisfatoriamente, exige-se do professor- formador não apenas uma prática constante de leitura literária, mas também um amplo conhecimento técnico e teórico dos estudos literários, assim como, dos estudos culturais. Enquanto os currículos de muitos cursos de Letras 
espalhados pelo país não forem revistos, o ensino de literatura continuará sendo reproduzido de forma técnica e pouco significativa.

\section{A literatura resiste ao tempo e nos ajuda a resistir}

Nas últimas três décadas o mundo testemunhou mudanças incríveis no campo da comunicação, da ciência e da tecnologia de modo geral. Estamos passando por uma revolução digital que expande seu alcance a todos os âmbitos sociais. Não há dúvida de que todos esses recursos tecnológicos proporcionam melhores condições de vida para aqueles que têm acesso a eles. No entanto, o acesso a todos esses recursos nem sempre é usado com discernimento e ética. Nunca antes a vida privada foi tão exposta e colocada em evidência, e muitas vezes, tal exposição tem resultados trágicos. Nem mesmo a modernidade com todos os seus aparatos e informação consegue afastar o ser humano da barbárie. "Portanto, podemos dizer que os mesmos meios que permitem o progresso podem provocar a degradação da maioria.” (CANDIDO, 2004, p.169).

Mesmo nos tempos atuais com tantos avanços tecnológicos, defendemos a leitura literária como um meio para resistir à barbárie social. Não importa o suporte, pode ser através do livro convencional, ou então, através dos meios digitais. O importante é que a experiência da leitura aconteça. Por essa razão, é primordial que o contexto escolar não negligencie seu papel no ensino de literatura, pois para muitas crianças e jovens a escola é o único espaço onde eles têm acesso ao livro e à leitura. Da mesma forma, é indispensável que os cursos de Letras preparem, de modo eficaz, os futuros profissionais para realizar um trabalho consistente e relevante na educação básica.

Entendendo que há coisas que só a literatura com seus meios específicos nos pode dar, não precisamos temer o seu esquecimento no mundo moderno. O que ela pode nos dar não é perecível ou ultrapassado. Seus atributos são sempre atuais e resistem ao passar do tempo. Precisamos, contudo, oportunizar espaços de leitura para que o potencial latente do texto literário se efetive e isso só acontece quando um livro é aberto. Para finalizar, compartilhamos com Sant'Anna a ideia de que o desenvolvimento de um país passa pela revolução silenciosa da leitura. "Com efeito, na modernidade, não existe nenhum país próspero que não tenha passado pela revolução silenciosa do livro e da leitura. E a leitura, como gesto de comunicação, tornou-se a chave para o ingresso no século XXI.” (2012, p.79).

\section{Referências}

BARTHES, R. Crítica e verdade. Tradução de Leyla Perrone-Moisés. São Paulo: Editora Perspectiva, 1970. 
BENJAMIN, W. O Narrador. In: Magia e técnica, arte e política: ensaios sobre literatura e história da cultura. Tradução de Sérgio Paulo Rouanet. 7.ed. São Paulo: Brasiliense, 1994. p.197-221.

CALVINO. I. Seis propostas para o próximo milênio: lições americanas. Tradução de Ivo Barroso. São Paulo: Companhia das Letras, 1990.

CANDIDO, A. O direito à literatura. In: Vários escritos. São Paulo/Rio de Janeiro: Duas Cidades/ Ouro sobre azul, 2004, $4^{\mathrm{a}}$ edição.

COMPAGNON, A. Literatura para quê? Tradução de Laura Taddei Brandini. Belo Horizonte: Editora UFMG, 2012.

HALL, S. A identidade cultural na pós-modernidade. Tradução de Tomaz Tadeu da Silva, Guacira Lopes Louro. Rio de Janeiro: DP\&A, 2006.

LEJEUNE, P. O pacto autobiográfico: de Rousseau à Internet. Tradução de Jovita Maria G. Noronha, Maria Inês C. Guedes. Belo Horizonte: Humanitas/ UFMG, 2008.

PETIT, M. A arte de ler: ou como resistir à adversidade. Tradução de Arthur Bueno e Camila Boldrini. São Paulo: Ed.34, 2009.

REZENDE, N. L. Apresentação ao leitor brasileiro. In: LANGLADE, G; REZENDE, N. L.; ROUXEL, A (Orgs.). Leitura subjetiva e ensino de literatura. São Paulo: Alameda, 2013.

ROUXEL, A. O advento dos leitores reais. In: LANGLADE, G; REZENDE, N. L.; ROUXEL, A (Orgs.). Leitura subjetiva e ensino de literatura. São Paulo: Alameda, 2013.

SANT’ANNA. A. R. O leitor, onde está o leitor? Ou a crise da escassez e do excesso. Revista Muitas Vozes. Ponta Grossa, v.1, n.1, p.65-80, 2012.

SARTRE, J. Que é a literatura? Tradução de Carlos Felipe Moisés. São Paulo: Editora Ática, 1989.

TODOROV, T. A literatura em perigo. Tradução de Caio Meira. Rio de Janeiro: DIFEL, 2010.

Recebido em 25/10/2013

Aprovado em 06/02/2014 